\title{
Portuguese marine fungi and the contribution of differential interference contrast (DIC) microscopy for their morphological identification
}

\author{
E. Azevedo $* * * * * * *$, M.F. Caeiro ${ }^{* * * * *}$ and M. Barata ${ }^{* * * *}$
}

*Departamento de Biologia Vegetal, Faculdade de Ciências da Universidade de Lisboa (FCUL), Campo Grande, Edifício C2 - 1749-016 Lisboa, Portugal

**Centro de Biologia Ambiental (CBA) da FCUL

***Centro de Estudos do Ambiente e do Mar (CESAM) da Universidade de Aveiro - Pólo FCUL

Marine fungi occur either in Open Ocean or in the intertidal zone of sandy beaches, salt marshes and mangroves, where their hosts and substrates are found. The development of morphological adaptations like appendages and sheaths of the spores are vital to the settlement and attachment to substrate surfaces, floatation and dispersion on seawater. The morphological features of these appendages and sheaths of spores also have an important role in the identification of marine fungi. Differential interference contrast (DIC) microscopy is an essential tool for the observation of these mucilaginous structures in marine fungi spores and was therefore applied to marine mycota from surveys along the Portuguese coast.

Since 1991 Portuguese marine fungi have been studied and characterized based on morphological identifications. The studied environments included salt marshes, sandy beaches and marinas. On these environments different substrates were collected such as plants and baits of Spartina maritima [1, 2, 3], different categories of drift substrates [3, 4] and Fagus sylvatica and Pinus pinaster baits [5]. These substrates, which had been exposed to different conditions of permanent and temporary submersion, were subjected to an initial examination under the stereoscope microscope in order to detect fruit bodies and spores of marine fungi. These structures were then observed in order to achieve the taxonomic identifications of these fungi, based on dichotomous keys for marine fungi.

To observe and characterize the wide variety of appendages and mucilaginous sheaths of the ascospores, basidiospores and conidia often invisible in the bright field of the light microscope, the use of DIC microscopy was implemented, because three-dimensional images are produced, highlighting them. The identified fungi were microphotographed with a Leica Wild MPS 52 with Fujichrome RTP- 135, 64T Tungsten.

The studies carried out with substrates subjected to conditions of permanent submersion highlighted the dominance of Ascomycota with unitunicate asci $[2,5]$. The unitunicate asci are thin - walled, persistent or early deliquescing, favoring ascospores release on marine environmental conditions (fig $1 \mathrm{a}, 1 \mathrm{~b}$ and $1 \mathrm{c}$ ). On the other hand, Ascomycota with bitunicate asci, were mainly detected on temporary submersion conditions [1, 3, 4]. These fungi presented asci with active spore discharge and mucilaginous sheaths that contributed to substrate attachment (fig. $2 \mathrm{a}$ and $2 \mathrm{~b}$ ). Ascospores and conidia presented morphological diversity on their appendages, which has particular importance on their success in marine environment (figs. 3, 4, 5, and 6).

Marine Mycologists are in agreement that the best technique to observe the appendages and sheaths of spores, often invisible in the bright-field microscope is the use of differential interference or phase contrast microscopy [6]. DIC microscopy was then applied to the observation of Portuguese marine fungi enabling to thoroughly characterize the structures essential to their morphological identifications.

\section{References}

1. Barata M., In: Fungi in Marine Enviroments, Hyde K.D. (ed.), Fungal Diversity Press, Hong Kong, China, pp.179-193, 2002.

2. Barata M., Ver. Iberoam. Micol., 23:179, 2006.

3. Figueira D. and Barata M., Mycologia, 99:20, 2007.

4. Azevedo E. et al., Mycologia, 104:623, 2012.

5. Azevedo E. et al., Nova Hedwigia, 90:52, 2010.

6. Jones E.B.G. et al., Fungal Divers, 35:1, 2009. 

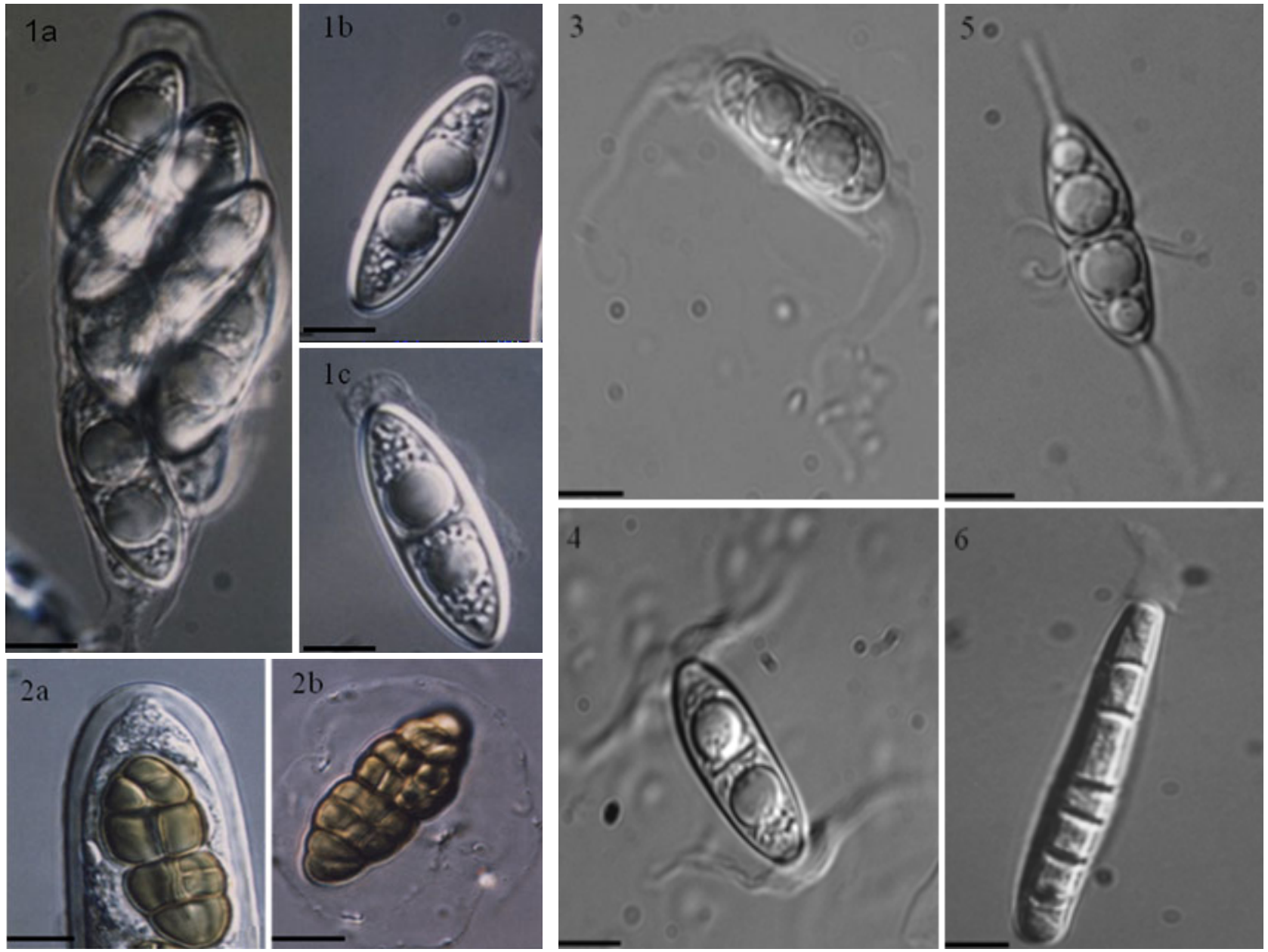

Fig. 1 - Tirispora unicaudata: 1a) unitunicate ascus with eight ascospores; 1b) ascospore with a polar appendage; $1 \mathrm{c}$ ) ascospore with an unfurling polar appendage. Bars $=10 \mu \mathrm{m}$.

Fig. 2 - Tremateia halophila: 2a) apex of a bitunicate ascus; 2b) ascospore with a gelatinous sheath. Bars $=12 \mu \mathrm{m}$.

Fig. 3 - Ceriosporopis halima: ascospore surrounded by a exosporic gelatinous sheath that is pierced at each apex by an outward growing appendage with variable length. Bar $=10 \mu \mathrm{m}$.

Fig. 4 -Remispora quadri-remis: ascospore with four radiating appendages at each apex. $\mathrm{Bar}=10 \mu \mathrm{m}$. Fig. 5 - Corollospora maritima: ascospore with polar and equatorial appendages. Bar $=10 \mu \mathrm{m}$. Fig. 6 Stagonospora sp.: conidium with seven cells and a gelatinous cap at the upper end. Bar $=5 \mu \mathrm{m}$. 